\title{
Does debarking intensity during the first cork extraction affect future cork thickness?
}

\author{
Joana A. Paulo ${ }^{1}$ (iD $\cdot$ Margarida Tomé ${ }^{1}$
}

Received: 13 February 2017 / Accepted: 23 August 2017 /Published online: 27 September 2017

(C) INRA and Springer-Verlag France SAS 2017

\begin{abstract}
- Key message The use of increasing debarking during the first harvest of cork oak trees (Quercus suber L.) had no effect on the secondary cork calliper (thickness) in one of the trials and had a small negative effect in a second trial. Little evidence was found that debarking coefficient is a useful index for the management of cork oak stands.

- Context The Portuguese national legislation defines, without the support of scientific data or knowledge, maximum values of debarking coefficients (ratio of debarking height and perimeter at breast height measured over cork). For the first debarking, this value is limited to 2.0.

- Aims The aim of this study was to determine the impact of increasing cork debarking coefficient on the calliper of the secondary cork extraction.

- Methods Trees were located in two sites, in distinct regions characterized by low or high productivity classes. Three debarking coefficients were considered: 1.5, 2.0 and 2.5.
\end{abstract}

Handling Editor: Andrew Merchant

\section{Contribution of the co-authors}

Joana Amaral Paulo: experimental design, data collection, data analysis and manuscript writing.

Margarida Tomé: experimental design, data analysis and manuscript revision.

Electronic supplementary material The online version of this article (https://doi.org/10.1007/s13595-017-0662-x) contains supplementary material, which is available to authorized users.

Joana A. Paulo

joanaap@isa.ulisboa.pt

Instituto Superior de Agronomia, Centro de Estudos Florestais, Forest Ecosystem Management under Global Change Research Group (ForChange), Universidade de Lisboa, Tapada da Ajuda, 1349-017 Lisbon, Portugal
The debarking coefficient for the first cork extraction was randomly selected for each tree. During the second debarking, a cork sample was taken from each tree. The samples were used for assessing secondary cork calliper. Differences in cork calliper were analysed using both correlation analysis and modelling approaches.

- Results Debarking intensity increase had a small negative effect on secondary cork thickness in the most inland site, while no effect was detected in the more coastal site.

- Conclusion In our experiment, debarking intensity had a significant but small effect in one site and no effect in other sites. Debarking coefficients not only should be defined according to legal constraints but also instead should be adapted considering tree and site characteristics.

Keywords Quercus suber L. · Montado · Debarking coefficient $\cdot$ Debarking height $\cdot$ Secondary cork $\cdot$ Cork thickness $\cdot$ Cork calliper

\section{Introduction}

Cork oak forests, also designated as montados, are one of the most extended high natural and cultural value ecosystems in the Mediterranean region (den Herder et al. 2017; Plieninger et al. 2015). These systems have been managed for centuries to engender the compatibility of cork production with agriculture and/or extensive grazing, but cork is frequently one of the most important sources of revenue for the landowners. Therefore, tree debarking is one of the most important management operations, not only because it results in the collection of the cork but also because the way the operation is carried out may affect the tree and cork growth in the following growth period (Costa et al. 2004; Costa et al. 2015; Natividade 1950; Pereira 2007). 
The immediate physiological response of the tree to the debarking operation has been researched at tree level by Correia et al. (1992), Hakam et al. (2012) and Werner and Correia (1996) and at stand level by Silva et al. (2015). Apart from for Hakam et al. (2012), no author found any relation between the tree response and the debarking intensity evaluated by debarking coefficient and by total debarked surface. Regarding a medium (annual) to long-term (period between two cork extractions) tree response, Costa et al. (2015), Fialho et al. (2001), Leal et al. (2008) and Oliveira et al. (2002) researched the effect of the debarking on radial growth and tree phenology, but none of the authors investigated the tree response to different debarking intensities.

One of the main concerns of landowners, managers and researchers regarding the management of the cork oak tree is the impact of the debarking intensity at a debarking event at tree age $t$, on tree and cork growth during the next cork growth period that will terminate in the debarking event at tree age $(t+9)$ (e.g. Oliveira and Costa 2012; Paulo et al. 2016). Debarking intensity may be measured by debarking height or number of debarked branches variables or computed as debarking coefficient or debarking surface values. The Portuguese national legislation defines maximum values for the debarking coefficients, defined as the ratio between debarking height measured along the tree stem and the debarked branches and the perimeter at breast height measured over cork. It restricts to a maximum of 2.0 for the first debarking, 2.5 for the second and 3.0 for the third and following debarking operations. The established values were suggested by Natividade (1950) based on expert judgement. These limits are clearly defined as upper limits, with the objective of protecting trees from overexploitation, but questions related to the most appropriate value for particular stands or trees remain open (Paulo et al. 2016). It is expected that several variables may be related to the tree response to the debarking, for example, stand growing conditions (site productivity), management operations (e.g. understory composition and management operations for its control) or tree characteristics (e.g. sanitary conditions, cork thickness). Natividade (1950) suggested a reduction of the proposed 3.0 debarking coefficient to 2.5 for trees with more than three debarked branches, highlighting the importance of tree structure and tree debarking surface on the definition of the debarking intensity. More recent research, based on representative data sets, is scarce in the literature. The need for longterm experiments and data collection in controlled trials largely explains the current state of the art regarding this subject. Paulo et al. (2016) and Pizzurro et al. (2010) indirectly discuss the effect of the debarking intensity on cork thickness, the first suggesting that other variables such as annual precipitation and site characteristics are more influential for cork thickness, and the second supporting the conclusions of Natividade (1950) that increasing debarking heights will result in a decrease in cork calliper. Both authors base their research on data collected from adult trees, of unknown age, and with an 'unknown management history', particularly in what concerns the debarking intensities that were applied in previous debarking operations. These characteristics of the data sets do not exclude a possible influence of the past debarking operations on the results.

The objective of the present research is to evaluate the effect of the debarking intensity, at the first cork extraction, on cork thickness extracted during the second debarking operation. This was carried out by the analysis of the cork thickness values, measured at tree level, in two distinct trials characterized by distinct soil and climate conditions. The trees in both sites had not been debarked prior to the treatments application, and for this reason, no co-effect of previous debarking disturbs the results.

\section{Materials and methods}

The research was developed on two distinct sites. The first site is located in a privately owned property called Machuqueira do Grou, located in the Ribatejo province, in the Coruche county (WGS84 coordinates: $39.132 \mathrm{~N},-8.343 \mathrm{~W}$ ). The second site is located at the Perímetro Florestal of Contenda, currently a municipal property under the joint management of the Municipality of Moura and the National Forest Authority. It is located in the Baixo Alentejo province, near the city of Barrancos in Moura county (WGS84 coordinates: $38.058 \mathrm{~N},-7.040 \mathrm{~W})$. The two sites are, from now on, referred to as MG (Machuqueira do Grou) and PFC (Perímetro Florestal of Contenda).

The stand of the MG site is characterized by an unevenaged structure, including a considerable percentage of young undebarked trees. It is managed as a traditional silvopastoral system: reduced number of animals per hectare (sheep) feeding on natural pasture and reduced implementation of mechanical understory control methods (one or two per cork growth rotation period made with mounted knifes or chains). The average number of trees per hectare is 145 , with a basal area under cork of $7.6 \mathrm{~m}^{2} \mathrm{ha}^{-1}$ and a crown cover percentage of $45 \%$. The stand includes older and adult trees, mixed with young non-debarked trees. The trees considered for the trial had similar diameter and were therefore considered to have approximately uniform age. The productivity of the site, assessed by the site index model from Paulo et al. (2015), was estimated at $16 \mathrm{~m}$ for the total height of the dominant trees at a base age of 80 years, corresponding to a high productivity class (Paulo et al. 2015).

The stand of the PFC site is characterized by an even-aged structure stand, installed between 1958 and 1964, and managed primarily for game production (Pinheiro 1997). Forest management in PFC was limited to understory control 
operations with mounted knifes or chains, carried out with a reduced frequency and in order to reduce fire risk. The average number of trees per hectare was 143, with a basal area under cork of $3.1 \mathrm{~m}^{2} \mathrm{ha}^{-1}$ and a crown cover percentage of $24.2 \%$. The productivity of the site, assessed by the site index model from Paulo et al. (2015), was estimated at $13 \mathrm{~m}$, corresponding to a low productivity class.

In the matter of soil and climatic conditions, the two sites are also very distinct (Table 1). Since the years at which cork growth took place were not the same for both sites, a comparison of the annual precipitation distribution over the years of cork growth at the two sites is shown in the figure available as supplementary material.

The selected trees were completely enclosed by virgin cork (undebarked trees) at the year of the trial installation. Due to legal constraints imposed by national legislation, only trees presenting a minimum value of $70 \mathrm{~cm}$ of perimeter at breast height over virgin cork were considered. All debarking operations took place in June. In the MG site, a total of 90 trees were randomly selected. These trees were debarked for the first time in 1995. The second debarking took place in 2005, on 72 trees. The remaining 18 trees were not found and presumed dead. In the PFC site, a total of 144 trees were selected among 8 existing permanent plots in the stand. These trees were debarked for the first time in 2003. The second debarking took place in 2012, on 134 trees. The ten remaining trees were dead and randomly distributed across four plots.

Table 1 Soil and climate characterization of the two sites were the trials were installed

\begin{tabular}{|c|c|c|}
\hline Variable & MG & $\mathrm{PFC}$ \\
\hline Predominant soil type ${ }^{a}$ & Podzols & Leptosols \\
\hline Lithology & Sandstone & Schist \\
\hline Soil depth $(\mathrm{cm})^{\mathrm{b}}$ & - & 40 \\
\hline Parent material & Sedimentary & Metamorphic \\
\hline Altitude & 79 to $173 \mathrm{~m}$ & 235 to $583 \mathrm{~m}$ \\
\hline Slope & 0 to $5 \%$ & 15 to $30 \%$ \\
\hline Annual precipitation ${ }^{\mathrm{c}}$ & $642 \mathrm{~mm}$ & $689 \mathrm{~mm}$ \\
\hline Annual minimum temperature ${ }^{c}$ & $9.5^{\circ} \mathrm{C}$ & $11.1^{\circ} \mathrm{C}$ \\
\hline Mean annual temperature ${ }^{c}$ & $16.0^{\circ} \mathrm{C}$ & $16.2{ }^{\circ} \mathrm{C}$ \\
\hline Annual maximum temperature ${ }^{c}$ & $22.5^{\circ} \mathrm{C}$ & $21.2^{\circ} \mathrm{C}$ \\
\hline Years of debarking & $1995 ; 2005$ & $2003 ; 2012$ \\
\hline
\end{tabular}

$M G$ high productivity class site, $P F C$ low productivity class site

${ }^{a}$ FAO soil group according to the IUSS Working Group WRB (2006) classification

${ }^{\mathrm{b}}$ Not available for MG site

${ }^{c}$ Average values for the 30-year period of 1961 to 1990 , computed for the closest national meteorological station from the network of the Portuguese Meteorological Service
On both sites and during each measurement, the following tree measurements were carried out: diameter at breast height before $\left(d_{i}\right.$ where $i=1,2$ for representing the first and second cork debarking operations, respectively) and after debarking ( $\mathrm{du}_{i}$ where $i=1,2$ for representing the first and second cork debarking operations respectively) and total height $\left(\mathrm{h}_{\mathrm{i}}\right.$ where $i=1,2$ for representing total height at the time of the first and second cork debarking operations). Virgin cork thickness (ctv) was computed as $\left(d_{1}-\mathrm{du}_{1}\right) / 2$. In the year of the first debarking stem height (hs), vertical debarking height (hdv), debarked length in the branches (lb) and perimeter at the middle section of the debarked branches (pb) were also measured. The two last measurements were only carried out when the debarking height was higher than the stem height. These measurements allowed the computation of two additional variables that characterize debarking intensity: total debarking height (hdtot) and total debarked surface (sd). hdtot is defined as the sum of the debarking length on the stem and on the branches. Total debarked surface is computed as the sum of the surface area of cylinders associated to the stem (characterized by hs and $\mathrm{du}$ ) and the branches (characterized by $\mathrm{lb}$ and $\mathrm{pb}$ ).

The debarking height to apply to each tree included in the trial was computed from a debarking coefficient (dcoef) randomly selected: 1.5 (below maximum legal limit), 2.0 (maximum legal limit) and 2.5 (above maximum legal limit). Table 2 presents summary values for the hdv, hdtot, sd and $\mathrm{du}_{1}$ variables on each site at the year of the trial installation (1995 at the MG site and 2003 at the PFC site). During the second debarking operation, a cork sample was collected in every tree at breast height. This sample was used for cork quality and cork thickness assessment. Cork thickness was measured before and after boiling. Cork boiling is an industrial standard post-harvest operation made for all raw corkboards, but not carried out on virgin or secondary cork (Pereira 2007). For this reason, cork thickness previous to the boiling operation (ct) was used as a response variable.

The analysis of the effect of the debarking intensity was carried out at two levels: individual tree and stand level. Distinct statistical approaches were considered for each level.

The analysis at the individual tree level consisted of the following:

- Graphical and correlation analysis of the relationship between the response variable secondary cork thickness (ct) and the following independent variables: diameter before and after debarking $\left(d_{1}, \mathrm{du}_{1}, \mathrm{du}_{2}\right)$, virgin cork thickness (ctv), vertical debarking height (hdv), total debarking height (hdtot), debarked surface (sd) and debarking coefficient (dcoef). Graphical analysis was made by means of scatter and box plots observation. Correlation analysis was carried out by the computation of the Pearson $r$ and Spearman $\rho$ correlation coefficients, for assessing linear and monotonic relationships respectively (McDonald 
Table 2 Summary statistics of tree variables at the establishment of the trials

\begin{tabular}{|c|c|c|c|c|c|c|c|}
\hline \multirow[t]{2}{*}{ Variable } & & \multicolumn{3}{|c|}{$\mathrm{MG}(n=90)$} & \multicolumn{3}{|c|}{$\operatorname{PFC}(n=144)$} \\
\hline & & 1.5 & 2.0 & 2.5 & 1.5 & 2.0 & 2.5 \\
\hline \multirow[t]{3}{*}{$\mathrm{hdv}(\mathrm{cm})$} & $\min$ & 102 & 136 & 170 & 80 & 125 & 165 \\
\hline & avg & 110 & 148 & 179 & 130 & 157 & 195 \\
\hline & $\max$ & 131 & 180 & 193 & 169 & 215 & 256 \\
\hline \multirow[t]{3}{*}{ hdtot $(\mathrm{cm})$} & $\min$ & 102 & 136 & 170 & 80 & 125 & 165 \\
\hline & avg & 110 & 150 & 182 & 130 & 158 & 197 \\
\hline & $\max$ & 131 & 200 & 215 & 169 & 224 & 287 \\
\hline \multirow[t]{3}{*}{$\mathrm{sd}\left(\mathrm{m}^{2}\right)$} & $\min$ & 0.452 & 0.637 & 0.865 & 0.500 & 0.638 & 0.823 \\
\hline & avg & 0.594 & 0.827 & 0.978 & 0.923 & 0.985 & 1.175 \\
\hline & $\max$ & 0.943 & 1.186 & 1.153 & 1.562 & 1.786 & 1.863 \\
\hline \multirow[t]{3}{*}{$\mathrm{du}(\mathrm{cm})$} & $\min$ & 16.9 & 16.6 & 18.1 & 15.0 & 15.3 & 15.6 \\
\hline & avg & 21.1 & 21.1 & 21.6 & 22.2 & 19.6 & 19.1 \\
\hline & $\max$ & 27.7 & 29.2 & 24.8 & 31.2 & 27.7 & 28.6 \\
\hline
\end{tabular}

$M G$ high productivity class site, $P F C$ low productivity class site, $h d v$ vertical debarking height, $h d t o t$ total debarking height (stem + branches), $s d$ total debarked surface (including branches), $d u$ - diameter at breast height (cm), 1.5, 2.0 and 2.5 debarking coefficient values
2014). This analysis was carried out with the PROC CORR procedure of the SAS 9.4 software.

- Linear modelling of the secondary cork thickness (ct) value as a function of tree variables $\left(d_{1}, \mathrm{du}_{1}, \mathrm{du}_{2}\right.$, ctv) and variables related to debarking height and intensity (hdv, hdtot, sd and dcoef). Due to the categorical feature of the debarking coefficient variable (dcoef), dummy variables associated to each category were created as suggested by Myers (1990): dcoef1.5 (assumes a value of 1 for trees debarked for a 1.5 dcoef and 0 for other trees) and dcoef 2.5 (assumes a value of 1 for trees debarked for a 2.5 dcoef and 0 for other trees). Trees debarked for a 2.0 dcoef present values of dcoef 1.5 and dcoef 2.5 equal to zero. While for the MG site a fixed effect model was suitable due to the nonexistence of any grouping structure of the tree data, for the PFC site, a mixed model approach was considered due to the nested structure of the data that presents trees inside plots (Pinheiro and Bates 2000). The modelling procedure was carried out with the PROC MODEL and PROC MIXED procedures of the SAS 9.4 software.

The general expressions of the fitted models are as follows:

$\mathrm{ct}_{i}=\alpha_{0}+\alpha_{1} X_{i}+\alpha_{2} Y_{i}+e_{i}$,

for MG site, where $\alpha_{0}, \alpha_{1}$ and $\alpha_{2}$ are fixed parameters, ct $_{i}$ is cork thickness of tree $i, X_{i}$ is one of the tree variables, $Y_{i}$ is a tree level variable related to debarking height or intensity and $e_{i}$ is the model error associated to tree $i$.

$\mathrm{ct}_{i, j}=\alpha_{0}+\alpha_{1} X_{i, j}+\alpha_{2} Y_{i, j}+u_{j}+e_{i, j}$ for the PFC site, where $\alpha_{0}, \alpha_{1}$ and $\alpha_{2}$ are fixed parameters, ct $_{i}$ is cork thickness of tree $i, X_{i}$ is one of the tree size variables, $Y_{i}$ is a tree level variable related to debarking height or intensity, $u_{j}$ is the $j$ plot random effect, and $e_{i}$ is the model error associated to tree $i$ in $j$ plot.

All variables were tested separately for significance $(\alpha=0.05)$ and biological meaning of the associated parameter. Models including more than one single variable were then tested considering the inclusion of the variables selected in the previous step. The final models were characterized and discussed in terms of mean square error (the smaller the better) and adjusted $r^{2}$ (the larger the better) for the case of linear fixed effect models and AIC (the smaller the better) for the case of linear mixed models. If the plot random effect $\left(u_{j}\right)$ was not significant in the final model defined for the PFC site, it was removed and the model was refitted as a linear fixed effect model.

The analysis at the stand level consisted of the following:

- Comparison of the median cork thickness value by the median test (McDonald 2014)

- Comparison of the cork thickness empirical distributions values by the Kruskal-Wallis test (McDonald 2014), for each site and for each debarking coefficient value $(1.5,2.0$ and 2.5). When the Kruskal-Wallis test rejected the null hypothesis of equal empirical distributions, these were again compared using the Kolmogorov-Smirnov tests for a two-sample comparison, therefore resulting in three tests: dcoef1.5 versus dcoef 2.0 , dcoef 1.5 versus dcoef 2.5 and dcoef 2.0 versus dcoef 2.5 . This analysis was carried out with the PROC NPAR1WAY procedure of the SAS 9.4 software, by the inclusion of the EDF, median and Wilcoxon options. 

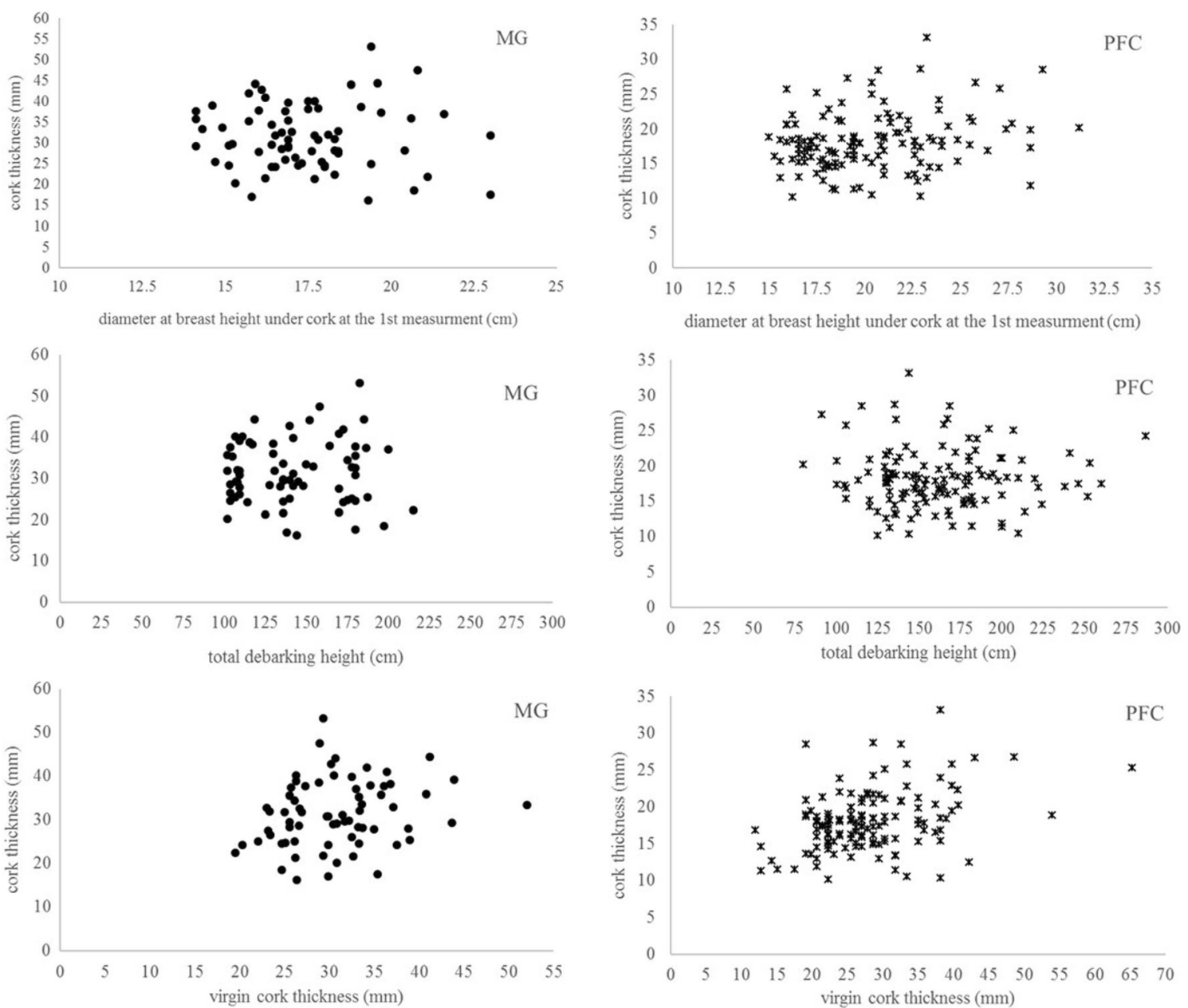

Fig. 1 Plot of cork thickness ( $\mathrm{mm}$ ) as a function of tree diameter at breast height (cm) after debarking (under cork), total debarking height (cm) and virgin cork thickness (cm). MG (left plots): high productivity class site. PFC (right plots): low productivity class site

\section{Results}

The graphical analysis did not evidence a relationship between secondary cork thickness (ct) and the independent variables (Fig. 1). The computation of the Pearson's and Spearman's correlation coefficients (Table 3) confirmed these results for all the variables related to debarking intensity (hdv, hdtot and sd). However, correlation coefficients showed a significant and positive relationship (both linear and monotonic relationships were significant for a 5\% significance value) between secondary cork thickness (ct), tree diameter $\left(d_{1}, \mathrm{du}_{1}\right)$ and virgin cork thickness (ctv), for the PFC site. A monotonic positive correlation was observed for the MG site (high productivity class) when relating secondary cork thickness (ct) with virgin cork thickness (ctv) variables.

Figure 2 shows the box plots of secondary cork thickness (ct) values grouped by site and by dcoef value. For the MG site, no difference was observed between the cork thickness (ct) among different debarking coefficient (dcoef) categories. For the PFC site, a decrease of the average and median values of secondary cork thickness (ct) was observed with the increase of debarking coefficient (dcoef).

Fitting of the linear models confirmed the results obtained by the graphical and correlation analysis for both sites. For the MG site, no variable included in the model was significant ( $\alpha=0.05$ ), either related to the tree size or debarking intensity. This confirmed the difficulty of predicting cork thickness when no previous tree level cork measurement is available (Paulo et al. 2016; Sánchez-González et al. 2007). The variable virgin cork thickness (ctv) was included in the model if a $10 \%$ significance level $(\alpha=0.10)$ was considered. The estimates of the model parameters and fitting statistics are presented in Table 4, showing a positive parameter estimate associated with the ctv variable $\left(\alpha_{1}\right)$ and a $p$ value of 0.0666 .

For the models developed for the PFC site, variables $d_{1}$, $\mathrm{du}_{1}, \mathrm{du}_{2}$ and ctv were significant $(\alpha=0.05)$ and associated with positive values. Variables hdv, hdtot and sd were not significant in the model (not shown). Dummy variables dcoef 1.5 and dcoef 2.5 confirmed the differences in ct average values already suggested by the box plots of Fig. 2 . The 
variance estimates associated with the plot random effect $\left(u_{j}\right)$ in the mixed model were not significant, allowing the rejection of the hypothesis that different plot conditions had significant effect on the secondary cork thickness (ct). For the following modelling process, the fixed effect model approach was considered for the PFC site. The models presenting the lower mean square error and higher adjusted $r^{2}$ values were the ones including variables $d_{1}$ or ctv (Table 4 ). When combining $d_{1}$ or ctv variables with the dummy variables dcoef1.5 and dcoef 2.5, two final models were obtained (Table 4). These models did not include the dcoef 2.5 dummy variable, indicating that no significant differences exist between trees debarked with dcoef of 2.0 and 2.5. Parameter estimates indicated that larger trees or trees with higher virgin cork thickness were associated with larger ct values and that the application of a dcoef equal to 1.5 would result in a $2.125-\mathrm{mm}$ increase of the ct value.

At the stand level, the differences were tested by the median and Kruskal-Wallis non-parametric tests, performed separately for each site (Table 5).

While no significant differences were present at the $\mathrm{MG}$ site, the rejection of the null hypothesis for the PFC site confirmed significant differences for the median values of ct between the three cork thickness distributions associated with different dcoefs. This led to the computation of the Kolmogorov-Smirnov tests for a two-sample comparison (Table 6).

For the PFC site, the cork thickness empirical distribution from trees debarked with a lower debarking coefficient (dcoef $=1.5)$ was significantly different from the ones debarked with a debarking coefficient of 2.0 or 2.5. The average value of cork thickness decreased from $19.9 \mathrm{~mm}$ (median $19.0 \mathrm{~mm}$ ) to $16.9 \mathrm{~mm}$ (median 17.1) going from dcoef of 1.5 to 2.5. Instead, no significant differences were found between the empirical distributions resulting from trees debarked with debarking coefficient of 2.0 and 2.5 (Table 6).

\section{Discussion}

The relationship between mature cork thickness and tree diameter after debarking has been researched by Pizzurro et al. (2010) and Sánchez-González et al. (2007) considering cork thickness before boiling and by Paulo et al. (2016) considering cork thickness after boiling. Despite this difference of the cork response variable, results suggest a positive (Paulo et al. 2016 and Sánchez-González et al. 2007) or null relationship (Pizzurro et al. 2010) between the two variables. Our results agree in suggesting a small and positive relationship between these variables, but only at the site located in an inland region, characterized by Leptosols and drier climate. Since none of the available and published data sets addressed the relationship of cork thickness and tree diameter for 

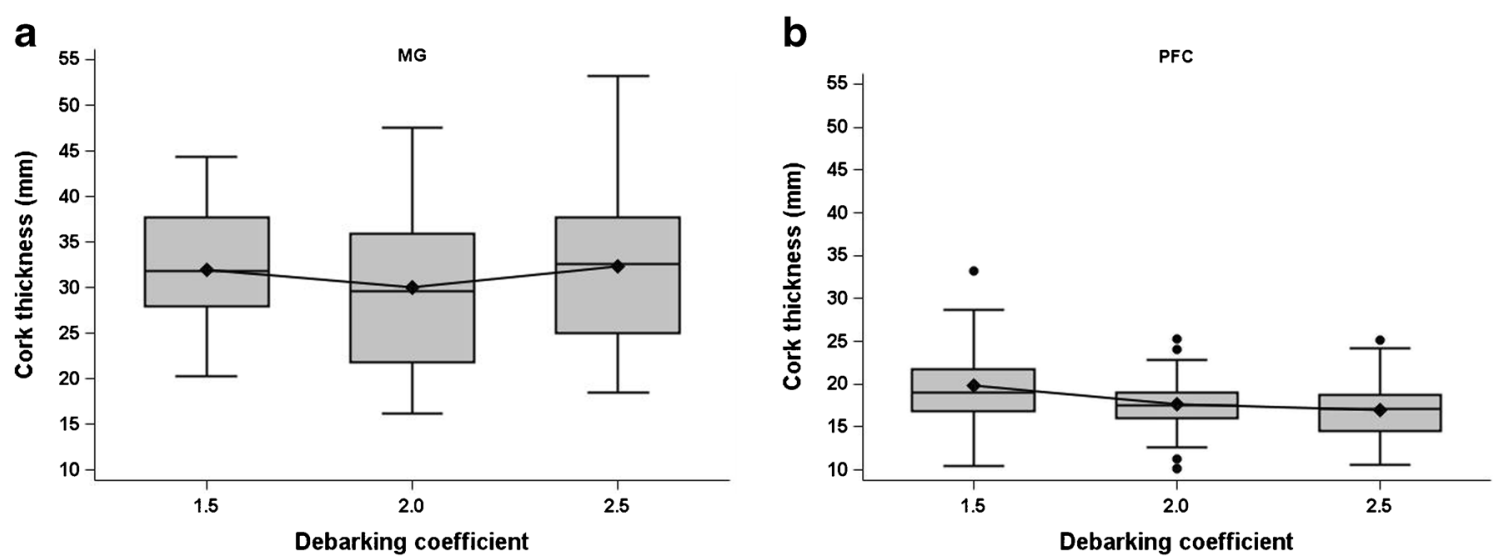

Fig. 2 Box plots for the values of secondary cork thickness, grouped by debarking coefficient value (1.5, 2.0 and 2.5). MG (left): high productivity class site. PFC (right): low productivity class site. Lines connect average values of secondary cork thickness

different site conditions (Paulo et al. 2015), open questions remain to be addressed regarding the different patterns of relationship of between these variables.

An additional and relevant characteristic of the data sets, used by Paulo et al. (2016), Pizzurro et al. (2010) and Sánchez-González et al. (2007), is the lack of information about the management of the sampled trees or stands (number of previous debarkings, previous debarking intensities, etc.), since this could help to understand the differences in the results when researching the relationship between cork thickness and debarking intensity. Pizzurro et al. (2010) reported a negative effect of the debarking intensity (assessed by total debarking height, debarking coefficient and debarking surface) while Paulo et al. (2016) concluded on a null relationship (assessed by vertical and total debarking heights and debarking coefficient). Our results suggest that the effect of distinct debarking intensity may be different according to the soil and climate conditions of the site, with limiting sites being associated with a significant and negative effect of increasing debarking intensities on secondary cork thickness.

Considering the impact of debarking coefficients in the revenue resulting from the debarking operation, one may observe that, for average values, the differences encountered in the two sites varied from 0 to $2 \mathrm{~mm}$. The largest differences were encountered in the PFC site, with Podzols and dry climate conditions, between the trees debarked with a debarking coefficient of 1.5 and others debarked with 2.0 or 2.5 coefficients. Looking at current cork price structures, it may be expected that these differences, although significant from a statistical point of view, will not have a large impact in the price of the resulting cork (Paulo and Tomé 2017).

Present results are restricted to the impact of the debarking intensity from the first cork extraction on secondary cork thickness, and no extrapolation should be made for cork extracted in following debarking operations and/or in adult trees. Research on the effect of long-term under- or overexploitation of cork requires the maintenance of the trials presented in this manuscript, the replication of the trials, and the inclusion of additional independent variables in the analysis, such as microsite soil chemical and physical properties (Corona et al. 2005). Meanwhile, the present results are key for the management of new cork oak plantations in Portugal and for other species able to be considered for bark extraction (Leite and Pereira 2017) such as the Quercus variabilis, a

Table 4 Parameter estimates in the models for cork thickness estimation

\begin{tabular}{|c|c|c|c|c|c|c|c|c|c|}
\hline \multirow[t]{2}{*}{ Site } & \multirow[t]{2}{*}{ model } & \multicolumn{2}{|l|}{$\alpha_{0}$} & \multicolumn{2}{|l|}{$\alpha_{1}$} & \multicolumn{2}{|l|}{$\alpha_{2}$} & \multirow[t]{2}{*}{ MSE } & \multirow[t]{2}{*}{ Adj- $-r^{2}$} \\
\hline & & Estimate & $\operatorname{Pr}>|t|$ & Estimate & $\operatorname{Pr}>|t|$ & Estimate & $\operatorname{Pr}>|t|$ & & \\
\hline MG & $\mathrm{ct}_{i}=\alpha_{0}+\alpha_{1} \mathrm{ctv}_{i}$ & 22.425 & $<0.0001$ & 0.287 & 0.0666 & & & 57.185 & 0.036 \\
\hline \multirow[t]{4}{*}{$\mathrm{PFC}$} & $\mathrm{ct}_{i}=\alpha_{0}+\alpha_{1} d_{1, i}$ & 10.404 & $<0.0001$ & 0.298 & 0.0006 & & & 15.755 & 0.080 \\
\hline & $\mathrm{ct}_{i}=\alpha_{0}+\alpha_{1} \mathrm{ctv}_{i}$ & 13.964 & $<0.0001$ & 0.149 & 0.0006 & & & 15.746 & 0.081 \\
\hline & $\mathrm{ct}_{i}=\alpha_{0}+\alpha_{1} d_{1, i}+\alpha_{2} \operatorname{dcoef}(1.5)_{i}$ & 11.964 & $<0.0001$ & 0.215 & 0.0193 & 1.828 & 0.0222 & 15.243 & 0.110 \\
\hline & $\mathrm{ct}_{i}=\alpha_{0}+\alpha_{1} \operatorname{ctv}_{i}+\alpha_{2} \operatorname{dcoef}(1.5)_{i}$ & 13.968 & $<0.0001$ & 0.124 & 0.0037 & 2.125 & 0.0044 & 14.895 & 0.130 \\
\hline
\end{tabular}

$M G$ high productivity class site, $P F C$ low productivity class site, $c t_{i}$ cork thickness of tree $i, c t v_{i}$ virgin cork thickness of tree $i, d_{1, i}$ diameter at breast height before cork debarking of tree $i, \operatorname{dcoef}(1.5)_{i}$ dummy variable associated to the dcoef ( 1 for trees debarked with a 1.5 dcoef and 0 for other trees), $\alpha_{i}$ model parameters, MSE mean square error, $A d j-r^{2}$ adjusted $r^{2}$ 
Table 5 Chi-square statistics of the median and Kruskal-Wallis tests, performed for the comparison of median value and empirical distribution comparison of ct from the three debarking coefficient: 1.5, 2.0 and 2.5

\begin{tabular}{lll}
\hline Trial & \multicolumn{1}{l}{ Test } \\
\cline { 2 - 3 } & Median & Kruskal-Wallis \\
\hline MG & $0.2507(0.8822)$ & $0.2142(0.8985)$ \\
PFC & $6.4534\left(0.0397^{*}\right)$ & $8.7571\left(0.0125^{*}\right)$ \\
\hline
\end{tabular}

Inside breaks the $p$ value associated to the test statistic

$M G$ high productivity class site, $P F C$ low productivity class site, $c t$ cork thickness

*The rejection of the test null hypothesis $(\alpha=0.05)$

species relatively abundant across temperate and subtropical areas in East Asia and presently under increase interest (e.g. Du et al. 2015; Zhou et al. 2010). Portuguese plantations began to be established at the end of the 1980s with the support of the common agricultural policy measures, and now they represent an important area in the country and a potential plus for national cork production (Coelho et al. 2012) and carbon sequestration (Palma et al. 2014). Average trees from these plantations have now achieved, or are close to achieving, the minimum perimeter value of $70 \mathrm{~cm}$ defined in national legislation that allows the first debarking to be carried out. National legislation also defines the maximum value of 2.0 for the debarking coefficient to apply during this operation. The established values, suggested by Natividade (1950) based on expert judgement and with a clear objective of protecting trees from overexploitation, should be considered as maximum values for good to average growth conditions that are associated with high and average Portuguese productivity classes proposed by Paulo et al. (2015). Meanwhile, in sites characterized by lower productivity classes, values under 2.0 are also considered, as they may contribute to an increase in the average cork thickness produced by the tree in the growth period immediately following.

Table 6 Chi-square statistics of two samples Kolmogorov-Smirnov test for the PFC site (average low productivity)

\begin{tabular}{ll}
\hline dcoef & ct \\
\hline $\mathrm{H}_{0}: f_{1.5}(\mathrm{ct})=f_{2.0}(\mathrm{ct})$ & $1.4350\left(0.0325^{*}\right)$ \\
$\mathrm{H}_{0}: f_{1.5}(\mathrm{ct})=f_{2.5}(\mathrm{ct})$ & $1.5850\left(0.0132^{*}\right)$ \\
$\mathrm{H}_{0}: f_{2.0}(\mathrm{ct})=f_{2.5}(\mathrm{ct})$ & $1.0283(0.2409)$ \\
\hline
\end{tabular}

Inside breaks the $p$ value associated to the test statistic

1.5, 2.0 and 2.5 debarking coefficients (dcoef), ct cork thickness

*The rejection of the test null hypothesis $(\alpha=0.05)$

\section{Conclusions}

Our results suggest that the impact of the increasing debarking intensity from the first debarking on cork thickness is small albeit different between sites. The debarking coefficient was significantly related to secondary cork thickness in the site characterized by Podzols, drier conditions and associated to average to a low productivity class but was not significant in the site characterized by Podzols and associated to a high productivity class. It is suggested that during the first debarking operation, the debarking coefficient values should be defined considering tree and site characteristics. The follow-up monitoring and sampling of the trials are needed in order to clarify the long-term tree response to increasing debarking intensities in consecutive cork debarking operations.

Acknowledgements The authors acknowledge Cristina Gonçalves, Sónia Pacheco Faias, Susana Barreiro, Sofia Leal and Sofia Knapic for their collaboration during measurements and sample collection.

Funding information Present research was supported by projects: SUBERWOOD (EU LRT-200-00701), REINFFORCE (INTERREG IVB), StarTree (EU Grant agreement 311919) and AgForward (EU Grant agreement 613520), under the Seventh Framework Program for Research and Technological Development and by the ReinForce project (INTERREG IVB operational programme). The first author developed this work under contract SFRH/BPD/96475/2013 established with Fundação para a Ciência e Tecnologia (Portugal). Centro de Estudos Florestais is a research unit supported by Fundação para a Ciência e Tecnologia (Portugal) under contract UID/AGR/00239/2013.

\section{References}

Coelho MB, Paulo JA, Palma JHN, Tomé M (2012) Contribution of cork oak plantations installed after 1990 in Portugal to the Kyoto commitments and to the landowners economy. For Policy Econ 17:59 68. https://doi.org/10.1016/j.forpol.2011.10.005

Corona P, Dettori S, Filigheddu MR, Scotti R (2005) Site quality evaluation by classification tree: an application to cork quality in Sardinia. Eur J Forest Res 124:37-46. https://doi.org/10.1007/s10342-004$0047-1$

Correia OA, Oliveira GM, Martins-Loução MA, Catarino FM (1992) Effects of bark-stripping on the water relations of Quercus suber L. Scientia gerundensis 18:195-204

Costa A, Pereira H, Oliveira A (2004) The effect of cork-stripping damage on diameter growth of Quercus suber L. Forestry 77:1-8. https://doi.org/10.1093/forestry/77.1.1

Costa A, Nunes LC, Spiecker H, Graça J (2015) Insights into the responsiveness of cork oak (Quercus suber L.) to bark harvesting. Econ Bot 69:171-184. https://doi.org/10.1007/s12231-015-9305-z

den Herder M, Moreno G, Mosquera-Losada R, Palma JHN, Sidiropoulou A, Freijanes JJS, Crous-Duran J, Paulo JA, Tomé M, Pantera A, Papanastasis VP, Mantzanas K, Pachana P, Papadopoulos A, Plieninger T, Burgess PJ (2017) Current extent and stratification of agroforestry in the European Union. Agric Ecosyst Environ 241: 121-132. https://doi.org/10.1016/j.agee.2017.03.005

Du B, Kang H, Zhu Y, Zhou X, Yin S, Burgess PJ, Liu C (2015) Variation of oriental oak (Quercus variabilis) leaf $\delta 13 \mathrm{C}$ across temperate and 
subtropical China: spatial patterns and sensitivity to precipitation. Forests 6:2296-2306. https://doi.org/10.3390/f6072296

Fialho C, Lopes F, Pereira H (2001) The effect of cork removal on radial growth and phenology of young cork oak trees. For Ecol Manag 141:251-258. https://doi.org/10.1016/S0378-1127(00)00333-9

Hakam A, Magne Takam M, Chokairi M, Alami Chantoufi N, Hamoutahra Z, El Alami A, Famiri A, Ziani M, Gril J (2012) Effect of bark stripping on the electrical impedance of Quercus suber leaves. Maderas Ciencia y tecnología 14:195-208. https:// doi.org/10.4067/S0718-221X2012000200007

IUSS Working Group WRB (2006) World reference base for soil resources 2006. $2^{\text {nd }}$ edition. World Soil Resources reports no. 103, FAO, Rome, $133 \mathrm{pp}$

Leal S, Nunes E, Pereira H (2008) Cork oak (Quercus suber L.) wood growth and vessel characteristics variations in relation to climate and cork harvesting. Eur J Forest Res 127:33-41. https://doi.org/10. 1007/s10342-007-0180-8

Leite C, Pereira H (2017) Cork-containing barks - a review. Front Mater 3:63. https://doi.org/10.3389/fmats.2016.00063

McDonald JH (2014) Handbook of biological statistics, 3rd edn. Sparky House Publishing, Baltimore

Myers RH (1990) Classical and modern regression with applications. Second edition. Duxbury Classic Series. 488 pp

Natividade JV (1950) Subericultura. Direcção Geral dos Serviços Florestais e Aquicolas, Lisbon, p 387

Oliveira G, Costa A (2012) How resilient is Quercus suber to cork harvesting? A review and identification of knowledge gaps. For Ecol Manag 270:257-272. https://doi.org/10.1016/j.foreco.2012.01.025

Oliveira G, Martins-Loução MA, Correia O (2002) The relative importance of cork harvesting and climate for stem radial growth of Quercus suber L. Ann For Sci 59:439-443. https://doi.org/10. 1051/forest:2002018

Palma JHN, Paulo JA, Tomé M (2014) Carbon sequestration of modern Quercus suber L. silvoarable agroforestry systems in Portugal: a YieldSAFE-based estimation. Agrofor Syst 88:791-801. https:// doi.org/10.1007/s10457-014-9725-2

Paulo JA, Tomé M (2017) Using the SUBER model for assessing the impact of cork debarking rotation on equivalent annual annuity in Portuguese stands. Forest Syst 26:e008, 11 pages. https://doi.org/10. 5424/fs/2017261-09931

Paulo JA, Palma JHN, Gomes AA, Faias SP, Tomé J, Tomé M (2015) Predicting site index from climate and soil variables for cork oak
(Quercus suber L.) stands in Portugal. New For 46:293-307. https:// doi.org/10.1007/s11056-014-9462-4

Paulo JA, Pereira H, Tomé M (2016) Analysis of variables influencing tree cork caliper in two consecutive cork extractions using cork growth index modelling. Agrofor Syst. https://doi.org/10.1007/ s10457-016-9922-2

Pereira H (2007) Cork biology, production and uses. Elsevier Science B.V, Amsterdam $346 \mathrm{pp}$

Pinheiro JMG (1997) Estabelecimento de parcelas permanentes de Quercus suber L. no Perímetro Florestal da Contenda. Relatório do trabalho de fim de curso de Engenharia Florestal. Instituto Superior de Agronomia, Lisboa

Pinheiro JC, Bates DM (2000) Mixed-effects models in S and S-Plus. Stat. And comput. series. Springer, New York, p 528

Pizzurro GM, Maetzke F, Veca DSLM (2010) Differences of raw quality cork in productive cork oak woods in Sicily in relation to stand density. For Ecol Manag 260:923-929. https://doi.org/10.1016/j. foreco.2010.06.013

Plieninger T, Hartel T, Martín-López B, Beaufoy G, Bergmeier E, Kirby K, Montero MJ, Moreno G, Oteros-Rozas E, Van Uytvanck J (2015) Wood-pastures of Europe: geographic coverage, social-ecological values, conservation management, and policy implications. Biol Conserv 190:70-79. https://doi.org/10.1016/j.biocon.2015.05.014

Sánchez-González M, Calama R, Cañellas I, Montero G (2007) Variables influencing cork thickness in Spanish cork oak forests: a modeling approach. Ann For Sci 64:301-312. https://doi.org/10.1051/forest: 2007007

Silva JFC, Correia A, Pinto C, David TS, Hernandez V, Pereira JS (2015) Descortiçamento do sobreiro: um stress para a árvore? In: Paulo JA, Oliveira V, Pereira H (ed) Book of abstracts of the $2^{\text {nd }}$ Centro de Estudos Florestais (CEF) conference from research to practice. Subject: Cork oak stands and cork oak. $25^{\text {th }}$ September 2015. Instituto Superior de Agronomia, Lisboa, 27 pp. http://hdl.handle. net $/ 10400.5 / 9280$

Werner C, Correia O (1996) Photoinhibition in cork-oak leaves under stress: influence of the bark-stripping on the chlorophyll fluorescence emission in Quercus suber L. Trees 10:288-292. https://doi. org/10.1007/BF02340774

Zhou JY, Lin J, He JF, Zhang WH (2010) Review and perspective on Quercus variabilis research. J Northwest For Univ 25:43-49 